\title{
Microglial Cells Contribute to Endogenous Brain Defenses after Acute Neonatal Focal Stroke
}

\author{
Joel V. Faustino, ${ }^{1 \star}$ Xia Wang, ${ }^{1,3 \star}$ Cali E. Johnson, ${ }^{1}$ Alexander Klibanov, ${ }^{4}$ Nikita Derugin, ${ }^{1}$ Michael F. Wendland, ${ }^{2}$ \\ and Zinaida S. Vexler ${ }^{1}$ \\ Departments of ${ }^{1}$ Neurology and ${ }^{2}$ Radiology, University of California, San Francisco, San Francisco, California 94143-0663, ${ }^{3}$ Department of Pediatrics, \\ Xiangya Hospital, Central South University, Changsha 410008, China, and ${ }^{4}$ Department of Medicine, University of Virginia, Charlottesville, Virginia 22908
}

Macrophages are viewed as amplifiers of ischemic brain injury, but the origin of injury-producing macrophages is poorly defined. The role of resident brain macrophages - microglial cells - in stroke remains controversial. To determine whether microglial cells exert injurious effects after neonatal focal stroke, we selectively depleted these cells with intracerebral injection of liposome-encapsulated clodronate before transient middle cerebral artery occlusion in postnatal day 7 rats. Phagocytosis of apoptotic neurons by activated microglia was poor in animals with unmanipulated microglia, and depletion of these cells did not increase the number of apoptotic neurons. Lack of microglia increased the brain levels of several cytokines and chemokines already elevated by ischemia-reperfusion, and also increased the severity and volume of injury, suggesting that microglial cells contribute to endogenous protection during the subacute injury phase. Then, to determine whether accumulation of reactive oxygen species in microglia adversely affects phagocytosis of dying neurons and contributes to injury, we delivered reduced glutathione (GSH) into microglia, again using liposomes. Remarkably, pharmacologically increased intracellular GSH concentrations in microglia induced superoxide accumulation in lipid rafts in these cells, further increased the brain levels of macrophage chemoattractants, and exacerbated injury. Together, these data show that microglia are part of the endogenous defense mechanisms and that, while antioxidants can protect the injured neonatal brain, high levels of reducing equivalents in activated microglia, GSH, trigger superoxide production, favor the reorganization of lipids, amplify local inflammation and exacerbate injury.

\section{Introduction}

Severe ischemic brain injury and higher macrophage density are linked in the adult. Resident brain macrophages, microglia, are thus seen as injurious. However, the origin of the macrophagesmicroglia or invading monocytes-may differentially affect injury; e.g., TNF $\alpha$ protects the brain from stroke when produced in activated microglia but injures it when produced in monocytes (Lambertsen et al., 2009). Microglia is the main cell type in the brain that provides immunosurveillance but can also be toxic (Kreutzberg, 1996). The microglial population is heterogeneous, and a subpopulation of microglia protects against stroke: injury is exacerbated after depletion of the proliferative microglia (Lalancette-Hébert et al., 2007) and ameliorated after injection of microglia into the ischemic brain (Imai et al., 2007). The type of stimulus and the local microenvironment-infectious, inflammatory, or anti-inflammatory_critically affect the microglial

\footnotetext{
Received April 27, 2011; revised July 13, 2011; accepted July 19, 2011.

Author contributions: Z.S.V. designed research; J.V.F., X.W., C.E.J., A.K., N.D., M.F.W., and Z.S.V. performed research; J.V.F., X.W., M.F.W., and Z.S.V. analyzed data; J.V.F. and Z.S.V. wrote the paper.

The work is supported by NIH Grants R01NS44025 (Z.S.V.) and R01NS055915 (Z.S.V.), American Heart Association Grant GIA 0855235 F (Z.S.V.), and China Scholarship Council (CSC 2007106816) (X.W.). We acknowledge Sarah Lee and Baomei Liu for technical help, and Drs. Patrick McQuillen and Donna Ferriero for useful discussions.

*J.V.F. and X.W. contributed equally to the manuscript.

Correspondence should be addressed to Dr. Zinaida S. Vexler, Department of Neurology, University of California, San Francisco, Box 0663, 521 Parnassus Avenue, San Francisco, CA 94143-0663. E-mail: Zena.Vexler@ucsf.edu.

DOI:10.1523/JNEUROSCI.2102-11.2011

Copyright $\odot 2011$ the authors $\quad 0270-6474 / 11 / 3112992-10 \$ 15.00 / 0$
}

phenotypes (Petersen and Dailey, 2004; Lalancette-Hébert et al., 2007). Apoptotic cells, for example, trigger the recognition and migratory cues on microglia (Lauber et al., 2003), and physical interaction between phagocytosing microglia and dying neurons suppresses inflammatory responses and switches the microglial phenotype from cytotoxic (M1) to protective (M2) (Lucas et al., 2006). In contrast, inflammatory mediators and reactive oxygen species (ROS), including superoxide $\left(\mathrm{O}_{2^{-}-}\right)$, halt phagocytosis and clearance of debris. The complexity of the modulatory role of microglia has also become apparent in neurogenesis (Monje et al., 2003; Butovsky et al., 2006). Thus, the role of microglia in stroke is controversial.

Immaturity critically affects the brain's susceptibility to ischemic and excitatory injury in rodents, particularly during the window of susceptibility during the first postnatal week (Ikonomidou et al., 1989). The inflammatory response in neonatal rodents is rapid after hypoxia-ischemia (H-I) (Hedtjärn et al., 2004) and focal stroke (Denker et al., 2007) and coincides with widespread neuronal apoptosis (Han et al., 2001; Manabat et al., 2003). Oxidative injury in part due to $\mathrm{O}_{2-}^{-}$accumulation is another major component of injury (Fullerton et al., 1998). Microglia can damage developing cerebellar neurons directly through $\mathrm{O}_{2-}-$ production (Marín-Teva et al., 2004). The differentiation status of microglia differs in immature and adult brain (Santambrogio et al., 2001), but the role of microglia in injury after neonatal stroke is largely unexplored.

We asked whether microglia are injurious after acute neonatal focal stroke and whether an increased intracellular antioxidant 

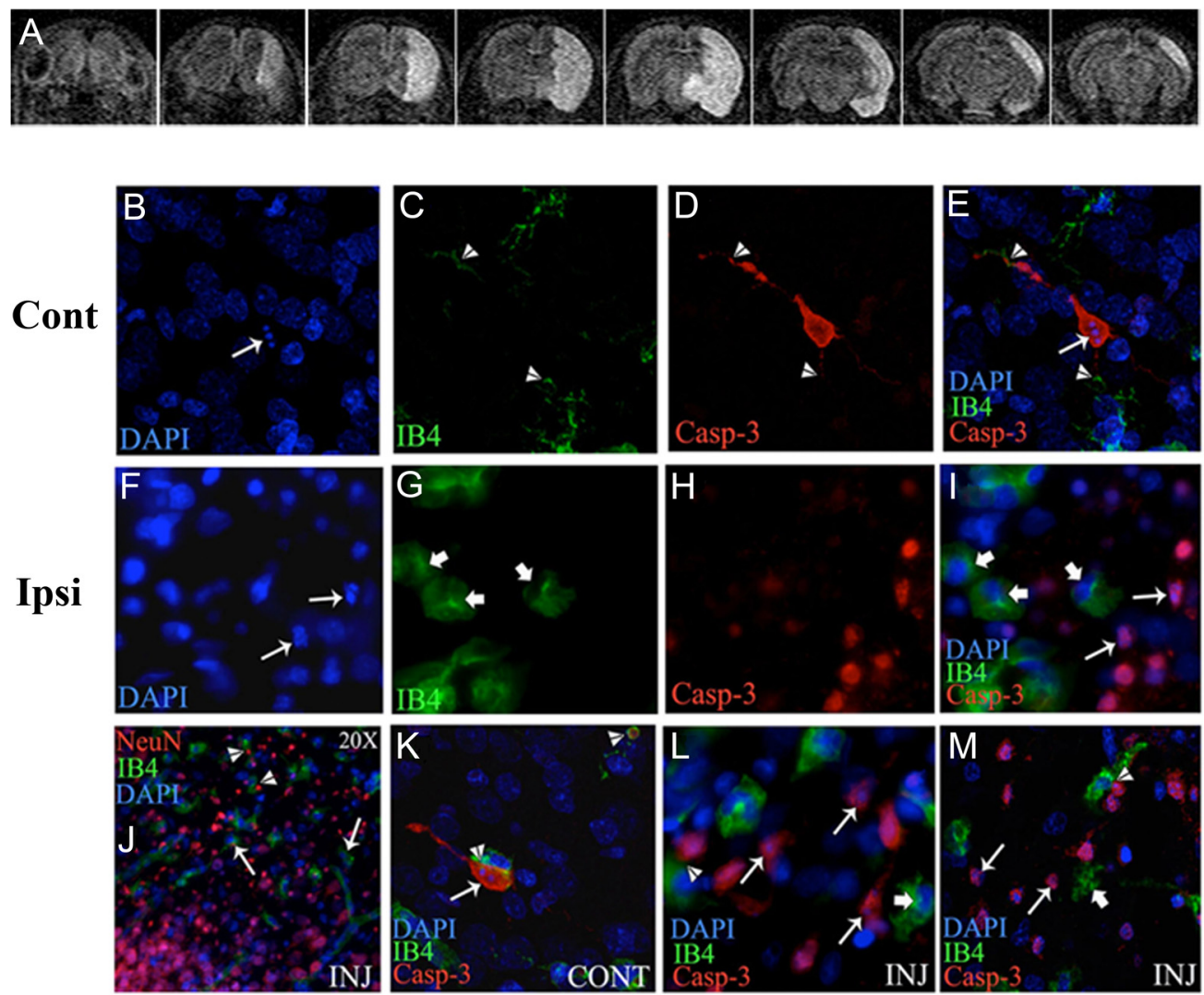

Figure 1. Neurons expressing cleaved caspase-3 are poorly phagocytosed by microglial cells in ischemic-reperfused regions $24 \mathrm{~h}$ after MCA0. $A$, The characteristic DWI pattern of injury during MCA0 is used for animal selection for the study. $\boldsymbol{B}-\boldsymbol{E}, \boldsymbol{K}$, In contralateral tissue, the few neurons that express cleaved caspase-3 (red) have either multiple contacts with IB4-positive cells (green, arrowheads) or are engulfed by microglia $(\boldsymbol{K}) . \boldsymbol{F}-\boldsymbol{I}, \boldsymbol{L}, \boldsymbol{M}, \mathbf{I n}$ injured tissue, neurons with activated caspase-3 (red) and apoptotic nuclei (blue, bis-benzimide, thin arrows) are abundant, and multiple microglial cells (green) with activated phenotype (thick arrows) are present in proximity to neurons undergoing caspase-3-dependent death. Remarkably few contacts between microglial cells and apoptotic neurons (arrowheads) are seen. J, NeuN (red)/IB4 (green). While microglia are sparse in normal tissue (left bottom corner), they accumulate in penumbra region (right top corner), but relatively few engulf neurons. Cont, Contralateral; Inj, injured. Magnification: $B-I, L, M, 63 \times ; J, 20 \times$.

concentration in these cells is beneficial. By delivering clodronate encapsulated into liposomes (Clod-lip) into neonatal brain, we depleted brain macrophages - which we have shown to be microglial cells, not invading monocytes, in acutely injured neonatal brain (Denker et al., 2007). With this unique opportunity to separate the effects of microglia from those of invading macrophages, we show that depletion of microglia enhances local inflammation induced by ischemia-reperfusion and increases injury severity, suggesting that microglia contribute to endogenous protection early after injury. We further show that a pharmacologic increase in reduced glutathione (GSH) in microglial cells induces, not reduces, $\mathrm{O}_{2-}$ production in microglia, favors lipid reorganization, amplifies local inflammation, and exacerbates injury.

\section{Materials and Methods}

Drug administration, animal model, and noninvasive injury identification by MRI. All animal research was approved by the University of California San Francisco Institutional Animal Care and Use Committee and was performed in accordance with the Guide for the Care and Use of Laboratory Animals (U.S. Department of Health and Human Services, Publication Number 85-23, 1985).

Liposomes that contain a lipid fluorescent dye, DiIC18(3)-distearate (DiI-lip), clodronate (dichloromethylene bis-phosphonate, Clod-lip), reduced glutathione (GSH-lip), or PBS (PBS-lip, empty liposomes) were prepared as previously described (Szoka and Papahadjopoulos, 1978) with modifications. Briefly, $20 \mathrm{mg}$ of 1-palmitoyl-2-oleoyl phosphatidylcholine, $10 \mathrm{mg}$ of cholesterol in $2 \mathrm{ml}$ of chloroform and $3 \mathrm{ml}$ of ethyl were mixed with $0.7 \mathrm{ml}$ of DiIC18(3) dye, clodronate $(100 \mathrm{mg} / \mathrm{ml})$ or $\mathrm{GSH}$ $(100 \mathrm{mg} / \mathrm{ml})$ in water, reverse emulsion prepared by sonication (XL2020, $40 \%$ power, $30 \mathrm{~s}$ ), and organic solvents were evaporated using rotary evaporator and a vacuum pump. Aqueous dispersion was filtered through a stack of two $0.4 \mu \mathrm{m}$ Nuclepore polycarbonate filters, assessed by laser light scattering using Nicomp 370 unit (Particle Sizing Systems) and kept in clodronate solution. The sizes of liposomes were $709 \pm 621$ $\mathrm{nm}$ for PBS and Clod-lip and $755 \pm 445 \mathrm{~nm}$ for GSH-lip. Based on $\mathrm{UV}$-spectroscopy of $\mathrm{Cu}^{2+}$-clodronate complex in the acidic conditions, clodronate entrapment rate was $20 \%$, and clodronate concentration remained unchanged over a three-month period. Intra-liposomal GSH concentration determined by spectrophotometry $(412 \mathrm{~nm})$ as the product of the reaction of dithio-bis-nitrobenzoic acid and GSH sulfhydryl group, was $28.6 \pm 5.5 \mathrm{mg} / \mathrm{ml}$. Liposomes were kept in GSH solution. Liposomes were centrifuged just before use to remove free clodronate or GSH from a solution, and pellet was resuspended in PBS.

Liposomes were administered into the right cortex of Sprague Dawley postnatal day 5 (P5) rats of either sex ( $3 \mu \mathrm{l}, 2.5 \mathrm{~mm}$ rostral, $2 \mathrm{~mm}$ lateral from bregma, and $2 \mathrm{~mm}$ deep through skull surface). At P7, a total of 188 pups were subjected to a transient $3 \mathrm{~h}$ intraluminal middle cerebral artery occlusion (MCAO), as described previously (Derugin et al., 1998) with modifications (Derugin et al., 2005); naive or sham-operated pups were used as controls.

Spin-echo echo planar diffusion-weighted MRI (DWI) was performed $2.5 \mathrm{~h}$ after MCAO to identify injured animals (Derugin et al., 2005); only animals with injury extending throughout the middle cerebral artery territory on DWI were used (Fig. $1 \mathrm{~A}$ ). Injury volume on DWI was determined in five consecutive $2 \mathrm{~mm}$ thick coronal sections. A total of 148 pups met inclusion criteria based on DWI during MCAO (79\%). The 
incidence of injury was $81 \%$ in the PBS-lip group and $75 \%$ in the Clod-lip group.

Western blot. Spectrin cleavage mediated by calpain and caspase- 3 was determined in lysates from injured and contralateral tissue using mouse anti-rat spectrin antibody (1:1000, Millipore). Expression of the CD36 $(\sim 88 \mathrm{kDa})$ was determined using rabbit anti-rat CD36 antibody (1:500, Novus).

Histology and immunofluorescence. Animals were perfused and postfixed with $4 \%$ PFA, and volumetric injury analysis was performed on a series of six $12 \mu \mathrm{m}$ thick cresyl violet-stained sections, beginning at the anterior genu of the corpus callosum (ImageJ, NIH). Injury volume was expressed as percentage of injured volume to volume of ipsilateral hemisphere. Doubleimmunofluorescence was performed on adjacent sections blocked in 10\% NGS/PBST and incubated overnight in 2\% NGS/PBST with rabbit anti-rat Ibal (1:200, Wako), mouse anti-rat CD68 (ED1; 1:50, Millipore Bioscience Research Reagents), or rabbit anti-cleaved caspase-3 antibodies (1:100, Cell Signaling Technology), followed by an appropriate Cy3-conjugated donkey anti-mouse and Cy2-conjugated donkey antirabbit antibodies (1:100, Jackson Laboratory), and costained with IB4 (1:100, Invitrogen) and DAPI. Z-stacks of 14-18 images captured at 1.5 $\mu \mathrm{m}$ intervals ( $40 \times$ oil objective, Zeiss Axiovert 100 equipped with Openlab Software, Improvision) were deconvolved (Volocity Software, Improvision) and analysis performed in three fields of view (FOVs) per region, in the ischemic core, penumbra, and matching contralateral tissue, using automated protocols for signal intensity threshold $(>2$ SD background in each channel) in a $1 \times 10^{6} \mu \mathrm{m}^{3}$ voxel. Caspase- $3^{+}$and CD $68^{+}$ objects with overlap $>10 \mu \mathrm{m}^{3}$ were considered colocalized. Iba1 ${ }^{+}$measurement protocols in contralateral hemisphere included a feature to "close objects" with 3-5 iterations to connect thin segmental cell processes.

In situ detection of $\mathrm{O}_{2^{-}}$production. A cell-permeable dye, hydroethidine (DHE, $5 \mathrm{mg} / \mathrm{kg}$, i.p.), was administered $3 \mathrm{~h}$ before animals were killed, followed by perfusion and postfixation in 4\% PFA. Z-stacks of images were obtained ( $40 \times$ oil objective, $0.4 \mu \mathrm{m} Z$-step) and image analysis performed in the deconvolved 3D image (Volocity software). The total number of cells intensely stained for oxidation products of $\mathrm{O}_{2-}{ }^{--}$ (Ox-DHE; 510/590 $\mathrm{nm}$ excitation/emission), the number of Iba ${ }^{+}$cells, along with the number of Ox-DHE endothelial cells, and the number of $\mathrm{Iba}^{+}$cells that interact with cells with the strong Ox-DHE signal, were determined. Counts were performed in 2-3 FOVs per region in penumbra, ischemic core and matching contralateral regions. Endothelial cells were visualized with IB4.

Adjacent slides were costained with the following organelle-specific markers: lysosomes (LAMP-2; 1:250, Abcam), autophages (LC3A/B; 1:50, Abcam), peroxisomes (PMP70; 1:40, Sigma), caveolin-dependent endosomes (clathrin heavy chain; 1:100, Cell Signaling Technology), and neutral lipids (BODIPY 493/503, Invitrogen). Rac1 was visualized in adjacent slides blocked in 10\%NGS/PBS and incubated on ice for 30 min with mouse anti-Racl antibody (1:500, BD Biosciences) in conjunction with rabbit polyclonal Ibal antibody or IB4.

Cytokine and chemokine measurements. Cytokine and chemokine concentrations were simultaneously quantified in a single sample from injured and contralateral brain tissue using a LINCOplex rat cytokine kit (LINCO Research), Luminex ${ }^{100}$ reader, and StatLIA software (Brendan Scientific) with a 5-parameter logistic curve-fitting (Denker et al., 2007).

The cell types producing cytokines and chemokines were identified using 4-channel immunofluorescence in slides incubated at room tem- perature overnight with cell type-specific antibodies for microglia (Iba1), neurons (NeuN; mouse-anti-rat; 1:100, Millipore), and reactive astrocytes (GFAP; mouse-anti-rat; 1:50; MP Biomedicals) in conjunction with antibodies for IL-1 $\beta$ (1:200; goat-anti-rat; R\&D Systems), TNF $\alpha$ (1:200; goat-anti-rat; R\&D Systems), MCP-1 (1:200; goat-anti-rat; Santa Cruz Biotechnology), or MIP-1 (1:200; rabbit-anti-rat; PeproTech). Appropriate secondary Alexa Fluor 488- or 568-conjugated antibodies were used. Macrophages and endothelial cells were identified by Alexa Fluor 647-conjugated IB4 (1:100; Invitrogen), and DAPI used to identify nucleus.

GSH measurements. GSH concentrations were measured in injured and contralateral brain tissue (homogenized in 5\% metaphosphoric acid) using a BIOXYTECH GSH/GSSG-412 colorimetric assay kit (Oxis Research) per manufacturer's instructions; calibration curve was used for data quantification.

Statistical analysis. Data were analyzed using ANOVA with post hoc testing (Fisher). Differences were considered significant at $p<0.05$.

\section{Results}

Neurons undergoing caspase-3-mediated death are poorly phagocytosed by activated microglia

Caspase-3-mediated neuronal death is a major contributor to injury after neonatal MCAO (Manabat et al., 2003). We first asked whether resident brain macrophages (i.e., activated microglial cells, cells with acquired ameboid morphology) effectively remove debris of neurons that die by caspase-3-mediated mechanisms. IB4/cleaved caspase-3 double-immunofluorescence showed that in the contralateral hemisphere, where neurons with cleaved caspase- 3 are rarely present, microglial cells recognize and wrap around portions of neurons with active caspase- 3 re- 

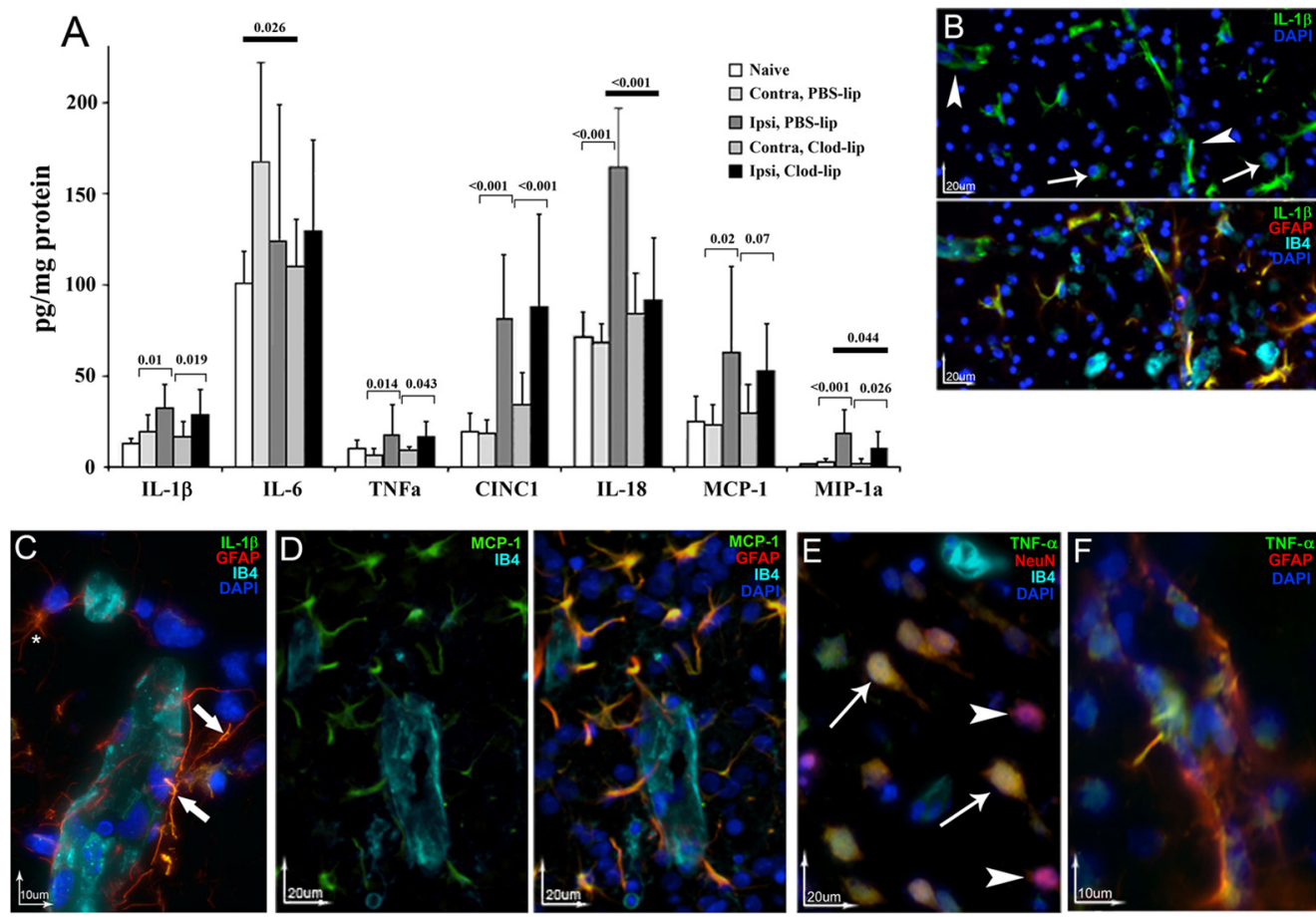

Figure 3. The elevated cytokine and chemokine levels $24 \mathrm{~h}$ after acute MCA0 are not reduced by Clod-lip. $\boldsymbol{A}$, The levels of several cytokines and chemokines are significantly increased in injured compared to matching contralateral tissue in each group, but with the exception of MIP-1 and IL-18 the levels are unchanged by Clod-lip. $n=7-8$ per group. Brackets, The significance levels between ipsilateral and contralateral hemisphere; thick straight line, the significance levels between PBS-lip and Clod-lip. B, IL-1 $\beta$ (green) is expressed by macrophages (thin arrows; IB4, turquoise), astrocytes (red), and endothelial cells (arrowheads; IB4, turquoise). Blue, DAPI. C, A subset of astrocytes (red, arrows) expresses IL-1 $\beta$ (green). *Astrocyte that does not express IL-1 $\beta$. Turquoise, IB4; blue, DAPI. $\boldsymbol{D}$, MCP-1 (green) is expressed by reactive astrocytes (red) and macrophages (IB4, turquoise). Blue, DAPI. $\boldsymbol{E}, \boldsymbol{F}$, TNF $\alpha$ (green) is expressed in morphologically integrant (E, arrows) but not in dying neurons ( $\boldsymbol{E}$, arrowhead) and in larger vessels and astrocytes $(\boldsymbol{F})$ in Clod-lip animals.

gardless of whether the neuron is in early (Fig. $1 B-E$ ) or more advanced (Fig. $1 K$, arrowhead) stages of degradation. In injured tissue, although multiple IB ${ }^{+}$cells were next to neurons with cleaved caspase-3 (Fig. 1 I, L,M, ameboid IB $4^{+}$cells), the majority of neurons undergoing caspase-3-dependent apoptosis were not engulfed and only a few (thin arrows) had contacts (arrowheads) with $\mathrm{IB} 4{ }^{+}$cells at both $8 \mathrm{~h}($ Fig. $1 F-I)$ and $24 \mathrm{~h}$ (Fig. $\left.1 L, M\right)$ after reperfusion. Therefore, the removal of apoptotic neurons by phagocytosis was limited.

\section{Depletion of activated microglia enhances local inflammation and does not protect}

Insufficient elimination of apoptotic cells has been shown to enhance necrosis and trigger inflammation in various models. Cytokine accumulation is rapid in ischemic-reperfused tissue after neonatal MCAO (Denker et al., 2007), and as a major source of inflammatory mediators after injury, brain macrophages can exacerbate injury. We have shown the brain macrophage population to be microglial cells, not invading monocytes, acutely after transient MCAO in neonatal rats (Denker et al., 2007). We therefore asked whether depletion of activated microglia protects against acute injury.

Macrophages have been effectively depleted by Clod-lip in various organs (Zito et al., 2001), but not in brain, due to low permeability of the blood-brain barrier (BBB) to conventional liposomes. We therefore delivered liposomes directly into the brain parenchyma to deplete microglia. Using fluorescently labeled liposomes (DiI-lip), we first characterized the cell types with accumulated liposomes. Consistent with the notion that macrophages easily engulf large particles (Aderem, 2002), massive accumulation of DiI-lip was observed in activated microglia in ischemic-reperfused tissue (Fig. $2 \mathrm{~A}$, ameboid IB $4^{+}$microglia with no processes and enlarged cell bodies) whereas accumulation was modest in ramified $\mathrm{IB} 4{ }^{+}$microglia in uninjured tissue (Fig. 2C). Dil-lip were rarely observed in reactive astrocytes (Fig. $2 B$ ), endothelial cells (Fig. $2 B$ ), or neurons (Fig. $2 A, C$ ) in both injured and uninjured regions, with only a few small liposomes in these cell types. We then established that Clod-lip injected into the brain at $\mathrm{P} 5$ reduced the number of resting $\mathrm{Iba1}{ }^{+}$microglia by P7 on the side of the injection from $51 \pm 14$ cells/FOV in untreated rats to $15 \pm 1$ cells/FOV in Clod-lip-treated rats $(n=4$ per group), and more gradually in the opposite hemisphere (32 \pm 7 cells/FOV). By $24 \mathrm{~h}$ Clod-lip reduced the number of $\mathrm{Iba}^{+}{ }^{+}$cells by $75 \%$ in the penumbra.

Clod-lip did not affect the incidence or volume of injury during MCAO, and neither did PBS-lip, as was evident from DWI (Fig. 2D). Also, the absence of activated microglia did not affect injury volume $24 \mathrm{~h}$ after reperfusion $(54.5 \pm 6.8 \%$ vs $50.6 \pm 6.1 \%$ of ipsilateral hemisphere in PBS-lip and Clod-lip, respectively). Given our previous data on the presence of both caspase-3dependent and -independent neuronal death within 4-24 h after MCAO (Manabat et al., 2003), we used cleavage of the structural protein spectrin as an indicator of the mode of cell death. Clodlip did not change the extent of caspase-3-mediated spectrin cleavage (Fig. $2 E$ ) but increased calpain-mediated spectrin cleavage in injured regions $(\sim 145 \mathrm{kDa}$ band, Fig. $2 E)$, indicating an increased excitotoxic injury component. The number of cells with cleaved caspase-3 was similar in both groups (Fig. $2 \mathrm{~F}$ ).

We then asked whether microglial depletion reduces the cytokine levels elevated by MCAO. Remarkably, the levels of the inflammatory mediators IL- $1 \beta$, TNF $\alpha$, CINC- 1 and MCP- 1 , which were significantly increased in injured tissue $24 \mathrm{~h}$ following 
MCAO, were not affected by microglial depletion (Fig. 3A). Only the elevated levels of IL-18 and MIP-1a were reduced by Clod-lip treatment. Using four-channel immunofluorescence, we examined the cellular sources of cytokine production in the absence of microglia. IL- $1 \beta$ expression was increased in a subset of vessels and in reactive astrocytes in injured regions (Fig. $3 B, C$ ) but not in cells of oligodendrocyte lineage (data not shown). Consistent with our previous report (Denker et al., 2007), MCP-1 was produced by several cell types, including endothelial cells and microglia. In the absence of microglia, MCP-1 expression was abundant in reactive astrocytes adjacent to penumbral regions and in a subset of larger vessels in the core (Fig. 3D). TNF $\alpha$ expression was increased within injured regions in neurons with relatively normal morphology but not in dying neurons (Fig. $3 E$ ) as well as in astrocytes, which were both associated (Fig. $3 F$ ) and not associated (data not shown) with vessels. Thus, several cell types contribute to the elevated cytokine levels and enhanced excitotoxic injury in the absence of microglial cells.

By $72 \mathrm{~h}$ after reperfusion, the overall number of Iba1 ${ }^{+}$cells and the number of cells with acquired scavenger receptor CD68 (ED1 ${ }^{+}$cells) expression were further increased in injured tissue in the PBSlip group (Fig. $4 A, B, E, F$ ), whereas the number of macrophages remained low in the Clod-lip group (Fig. 4C-F). The continuing acquisition of CD68 on microglia in the PBS-lip group or the lack of CD68expressing cells in the Clod-lip group did not affect the number of neurons with cleaved caspase- 3 within $72 \mathrm{~h}$ after reperfusion (Fig. $4 G$ ), consistent with the notion of a low rate of engulfment (Fig. 4G). Clod-lip further increased the already elevated levels of TNF $\alpha$, MIP-1a, MCP- 1 and CINC- 1 in injured tissue, compared with PBS-lip (Fig. 4H). Also, injury volume was significantly increased in the Clod-lip group (Fig. $4 I$ ). Based on similar volume of initial injury on DWI during MCAO in both groups (Fig. $2 \mathrm{D}$ ), injury exacerbation observed at $72 \mathrm{~h}$ occurred during reperfusion, and the increased injury was not due to the overall change in brain size or edema, as volumes of contralateral hemispheres were similar in both groups. Therefore, depletion of microglial cells before neonatal focal stroke exacerbates, rather than reduces, early injury and increases accumulation of inflammatory mediators, suggesting that even a limited extent of clearance of apoptotic neurons by activated microglia in acutely injured neonatal brain is protective.

Increased GSH concentration in microglial cells alters cell morphology but does not affect phagocytosis of dying neurons

Data by us and others have shown that neonatal brain injury is mediated by $\mathrm{O}_{2^{--}}$(Fullerton et al., 1998; Sheldon et al., 2004) and that increased activity of $\mathrm{H}_{2} \mathrm{O}_{2}{ }^{--}$using enzymes glutathione
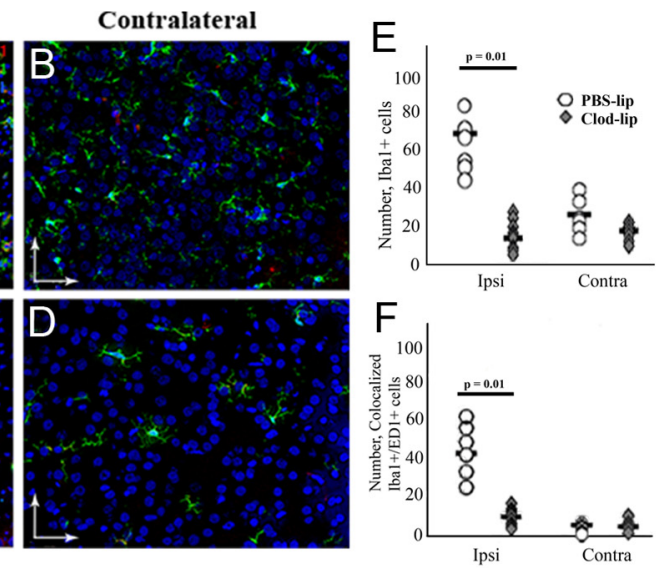

$\mathrm{H}$

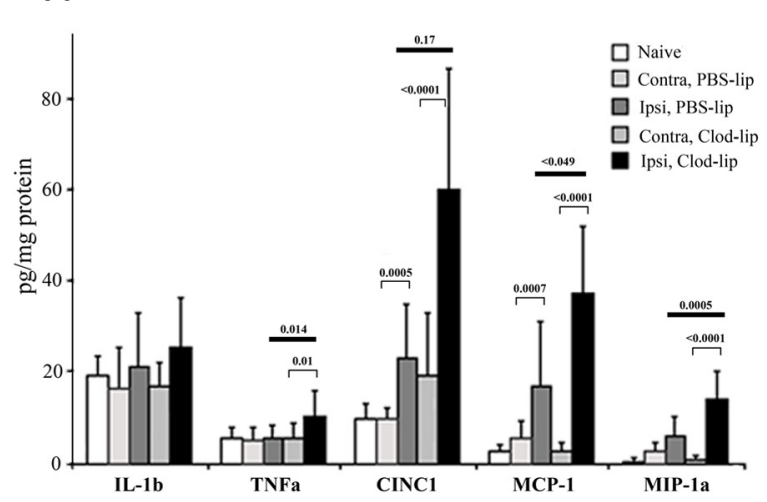

Figure 4. Depletion of microglia increases cytokine and chemokine accumulation and exacerbates injury $72 \mathrm{~h}$ after reperfusion. $\boldsymbol{A}-\boldsymbol{D}$, In PBS-lip-treated pups, Iba ${ }^{+}$cells are abundant in the ischemic core ( $\boldsymbol{A}$, the activated phenotype) and in contralateral hemisphere ( $\boldsymbol{B}$, the resting phenotype). In Clod-lip-treated pups, the number of Iba $1^{+}$cells remains significantly lower than in pups in both injured $(\boldsymbol{C})$ and contralateral $(\boldsymbol{D})$ tissue. Double-labeled Iba ${ }^{+} / \mathrm{ED} 1^{+}$are predominantly seen in the 列 PBS-lip-treated pups. $n=7-8$ per group. $I$, Clod-lip treatment increases volume of histological injury in pups during subacute injury phase (Nissl staining), $n=10-13$ per group. Black bars, Medians.

peroxidase and catalase as well as better preserved levels of GSH are protective (Lafemina et al., 2006). We asked whether protection of the neonatal brain from stroke could be achieved by enhancing antioxidative metabolism selectively in microglia.

Again using liposomes, we delivered GSH into microglia and showed that GSH concentration, which was significantly reduced in injured regions by $24 \mathrm{~h}$ after reperfusion in both untreated $(61.2 \%)$ and PBS-lip-treated rats (53.7\%), was better preserved in injured tissue following GSH-lip administration (71.6\%) (Fig. $5 A$ ). We then showed that GSH-lip treatment did not affect the number of Ibal ${ }^{+}$microglia in the ischemic core or in the penumbra (Fig. 5B-E). 3D reconstruction data analysis showed, however, that compared with PBS-lip, GSH-lip significantly affected morphology of $\mathrm{Iba}^{+}{ }^{+}$cells in injured regions, resulting in increased volume and surface area, but did not affect cell morphology in the contralateral hemisphere (Fig. $5 F, G$ ). Knowing that spreading of microglial cells is typically associated with increased phagocytosis, we determined the effects of GSH-lip on expression of the scavenger receptors. The surface area occupied by CD68 (ED1 ${ }^{+}$cells) was significantly increased in both the core and penumbra in both groups, more so in the GSH-lip group (Fig. $5 \mathrm{H}$ ), but the number of $\mathrm{CD} 8^{+}$cells was similar in both groups (Fig. 6A). Expression of another type of scavenger recep- 

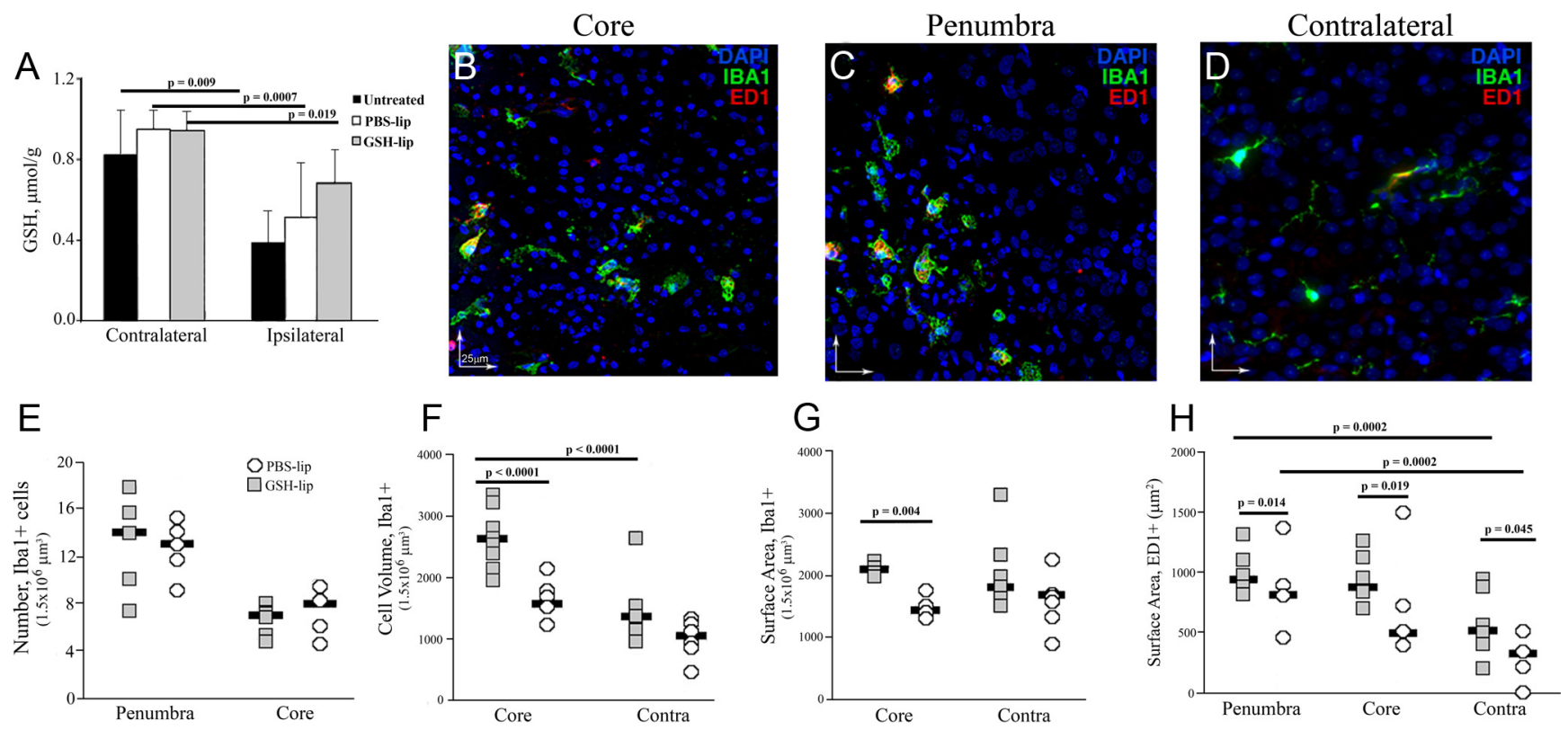

Figure 5. GSH-lip treatment partially restores GSH levels depleted by MCAO and alters microglial morphology in ischemic-reperfused brain regions. $A$, GSH concentration is significantly reduced in injured regions in both untreated and PBS-lip-treated pups and is more preserved in GSH-lip-treated pups at $24 \mathrm{~h}$ after reperfusion. $n=6-9$ per group. $\boldsymbol{B}-\boldsymbol{D}$, Examples of Iba ${ }^{+} /$ED $1^{+}$cells in ischemic core $(\boldsymbol{B})$, penumbra $(\boldsymbol{C})$ and contralateral cortex $(\boldsymbol{D})$ of a pup treated with GSH-lip. Green, Iba1; red, ED1; blue, DAPI. $\boldsymbol{E}$, The number of Iba ${ }^{+}{ }^{+}$cells in ischemic core and penumbra is unaffected by GSH-lip treatment. $\boldsymbol{F}, \boldsymbol{G}$, Volume $(\boldsymbol{F})$ and surface area $(\boldsymbol{G})$ of $\mathrm{lba}{ }^{+}{ }^{+}$cells are significantly increased by GSH-lip in injured regions. Black bars, Medians. $\boldsymbol{H}$, Surface area of ED1 ${ }^{+}$cells is significantly increased by GSH-lip. Black bars, Medians.

tor, CD36, while significantly increased in injured regions in both groups, was severalfold higher in the GSH-lip group (Fig. 6B). However, the number of cells with cleaved caspase-3 was similar in both groups $24 \mathrm{~h}$ after reperfusion (Fig. 6C), demonstrating that higher intracellular GSH concentration in activated microglia is not associated with increased removal of neurons that undergo caspase-3-mediated death.

GSH-lip treatment does not reduce $\mathrm{O}_{2-\text { - }}$ production in endothelial cells induced by injury but potentiates $\mathrm{O}_{2}$ production in microglia

To determine the effects of GSH-lip on the pattern of $\mathrm{O}_{2--}$ production induced by injury, we used hydroethidine, a dye which gives fluorescence products during its oxidation by $\mathrm{O}_{2-}^{--}$. There was no strong Ox-DHE signal at $1-6 \mathrm{~h}$ after reperfusion (data not shown) but a profoundly increased Ox-DHE fluorescence was observed in a subset of vessels, either in a single or in multiple cells per vessel (Fig. 6D,E) within injured regions $24 \mathrm{~h}$ after MCAO. Only a relatively weak $\mathrm{Ox}-\mathrm{DHE}$ signal was seen in other cell types, including Iba ${ }^{+}$cells, in reperfused tissue of untreated and PBS-lip-treated rats, with the range of signal intensities from barely over background to a relatively intense signal. Whether the pattern was diffuse or with vesicular appearance, Ox-DHE signal intensity was substantially lower than in the vasculature. No noticeable Ox-DHE signal was detected in the contralateral hemisphere or in the ipsilateral cingulate, an uninjured region in our model.

$\mathrm{O}_{2--}$ accumulation in endothelial cells was unchanged by GSHlip consistent with low accumulation of liposomes in these cells. Considering that $\mathrm{O}_{2^{-}}$accumulated in endothelial cells can attract microglial cells, we examined whether $\mathrm{Ibal}^{+}$cells and cells with strong Ox-DHE signal interact. $\mathrm{Ibal}^{+}$cells were observed proximate and distant from $\mathrm{O}_{2-}$ - producing vessels in both the PBS-lip and GSH-lip groups, but based on $3 \mathrm{D}$ analysis of $\mathrm{Ibal}^{+} / \mathrm{Ox}-\mathrm{DHE}^{+}$, the number of Ibal ${ }^{+}$cells in direct contact with dying neurons (Fig. $6 \mathrm{~F}$ ) or in contact with cells producing high $\mathrm{O}_{2-}^{-}$levels (Fig. $6 G$ ) was not affected by GSH-lip. The number of endothelial cells with high $\mathrm{O}_{2^{-}}$ levels in injured tissue was also unaffected by GSH-lip (Fig. $6 H$ ), suggesting that attraction of phagocytes or removal of debris does not directly depend on high $\mathrm{O}_{2-}^{-}$concentration.

Following GSH-lip treatment, $\mathrm{O}_{2-}^{-}$accumulation occurred in vesicles in a subset of activated microglia (Fig. 7) in addition to increased $\mathrm{O}_{2-}$ - production in endothelial cells. While Ox-DHE signal intensity ranged in vesicles of different size, a stronger signal was always seen in vesicles much larger than intracellular organelles (Fig. $7 A, B)$. In many $\mathrm{Ibal}^{+}$cells $\mathrm{Ox}$-DHE was either in association with the plasma membrane or membrane leaflet (Fig. $7 C, D$ ). The frequency of such a pattern of $\mathrm{O}_{2--}$ accumulation was significantly higher in the GSH-lip than in the PBS-lip group (Fig. 7E). Organellespecific markers for lysosomes, early endosomes, peroxisomes, and autophages, used in conjunction with DHE, did not show any particular colocalization pattern. In fact, vesicles with accumulated $\mathrm{O}_{2^{--}}$ were larger than individual organelles. Probing for neutral lipids showed that the Ox-DHE signal overlapped with lipid rafts and that compared PBS-lip (Fig. $7 F, G$ ), in GSH-lip animals the size of lipid rafts was increased (not shown). GSH-lip also induced recruitment of a small GTPase Rac 1 to lipid rafts (Fig. $7 H$ ).

Thus, strikingly, a shift in redox balance in activated micrglia does not affect $\mathrm{O}_{2--}$ accumulation in injured vessels but potentiates $\mathrm{O}_{2^{--}}$accumulation in lipid rafts, Racl recruitment to the membrane, and the assembly of lipid raft domains in activated microglia. Interestingly, both the temporal and cell-originspecific patterns of $\mathrm{O}_{2--}$ accumulation are different after adult (Cho et al., 2005) and neonatal MCAO.

\section{Increased intracellular GSH concentration in activated} microglia exacerbates subchronic injury after neonatal stroke Finally, we asked whether increased intracellular GSH concentration in activated microglia reduces injury. Although significant increases in the levels of IL- $1 \beta$, IL-18, TNF $\alpha$, CINC-1, MCP-1, and MIP- $1 \alpha$ occurred in injured tissue in both groups, only 
the levels of the microglia/macrophage chemoattractant proteins MCP-1 and MIP- $1 \alpha$ were further elevated in injured tissue by GSH-lip $72 \mathrm{~h}$ after reperfusion (Fig. 8 B), consistent with selective manipulations of microglial metabolism.

Histological analysis showed similar injury volume at $24 \mathrm{~h}$ after reperfusion (Fig. $8 A$ ), but a significantly larger injury at $72 \mathrm{~h}$ in the GSH-lip group (Fig. 8C). The relative sizes of the ipsilateral and contralateral hemispheres were unaffected. Consistent with our previous observations in untreated pups (Derugin et al., 2005), volume of injury was reduced over time in the vehicle group but it was adversely affected by GSH-lip treatment.

Together, these data suggest that, although antioxidative therapeutic strategies protect the neonatal brain against ischemia-reperfusion injury, a fine balance between reduced and oxidized glutathione in activated microglial cells is needed to maintain the redox state and function of these cells. A shift toward higher antioxidant concentration potentiates $\mathrm{O}_{2-}$ - in lipid fractions of these cells and exacerbates early injury by amplifying local inflammation.

\section{Discussion}

We show for the first time that depletion of microglial cells exacerbates injury after neonatal stroke in rodents. While microglial cells poorly engulf neurons that undergo caspase-3-mediated apoptosis, microglial depletion enhances excitotoxic injury and further increases the cytokine and chemokine production already induced by ischemia-reperfusion. We further show that, although antioxidants generally protect the neonatal brain from ROS accumulation and ischemia-related injury, pharmacologic increase in intracellular GSH selectively in microglial cells potentiates $\mathrm{O}_{2^{--}}$generation in activated microglia, induces lipid raft domain assembly, enhances neuroinflammation, and amplifies injury.

Macrophages accumulating in the brain after stroke could be of two types - resident activated microglia and differentiated invading monocytes - and they could contribute to injury differently (Lambertsen et al., 2009), but the tools to tell the two populations apart are limited. To distinguish their effects on injury, we focused on the early post-reperfusion period, when macrophages consist of microglia rather than infiltrating peripheral monocytes (Denker et al., 2007). We first confirmed that liposomes distribute throughout the brain, with a marked accumulation in ameboid microglia, a considerably lower accumulation in resting microglia, and only an occasional presence in neurons and astrocytes. Clod-lip depleted most of the resting microglia throughout the brain before MCAO (faster on the injected side), and, as expected, activated microglia were depleted more effectively than resting microglia. Compared with untreated pups, the size of injury during MCAO (DWI) or at $24 \mathrm{~h}$ (Nissl) was not affected by PBS-lip or Clod-lip
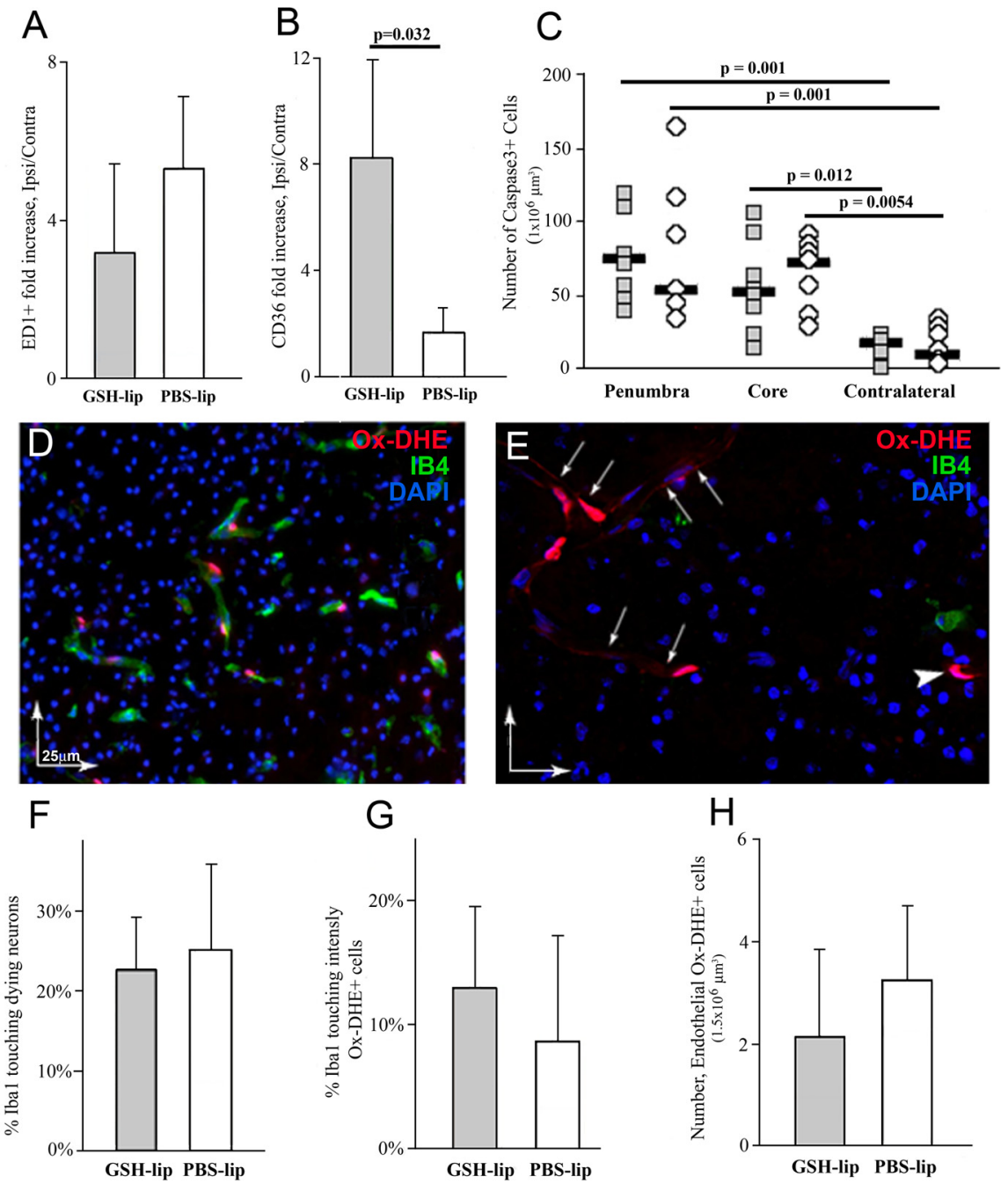

Figure 6. Administration of GSH-lip does not affect phagocytosis of apoptotic neurons or $\mathrm{O}_{2}-$ accumulation in endothelial cells after neonatal stroke. $\boldsymbol{A}, \boldsymbol{B}, \mathrm{At} 24 \mathrm{~h}$ after reperfusion, a unilateral increase in expression of the scavenger receptors $C D 68\left(\boldsymbol{A}, \mathrm{ED} 1^{+}\right.$ cells with high $0_{2}-$ that interact with lba ${ }^{+}$cells $(\boldsymbol{G})$ or the number of endothelial cells with strong $0 \mathrm{x}-\mathrm{DHE}(\boldsymbol{H})$ are not affected by GSH-lip treatment. $n=5-6$ per group.

administration, but injury shifted from apoptotic toward necrotic, and injury volume gradually increased in the absence of microglia.

Microglia could affect injury in several ways, including modulation of cell-cell communication, production of growth factors, cytokines and chemokines, and removal of cell debris. Production of inflammatory cytokines by microglia/macrophages is thought to contribute to injury after stroke in the adult, but in the neonate the significantly elevated levels of IL- $1 \beta$, IL$1 \alpha, \mathrm{CINC} 1$, and MCP-1 at $24 \mathrm{~h}$ remained largely unchanged in the absence of microglia, and the chemokine levels had increased further by $72 \mathrm{~h}$. Although the production of additional inflammatory mediators in the absence of microglia seems paradoxical, activated endothelial cells and astrocytes serve as sources of cytokines and chemokines, whereas the neuronal subpopulation contributes to TNF $\alpha$ production in injured regions. It is possible (but unlikely) that dying microglia induce cytokine production by directly stressing other cells after injury, because microglia are 

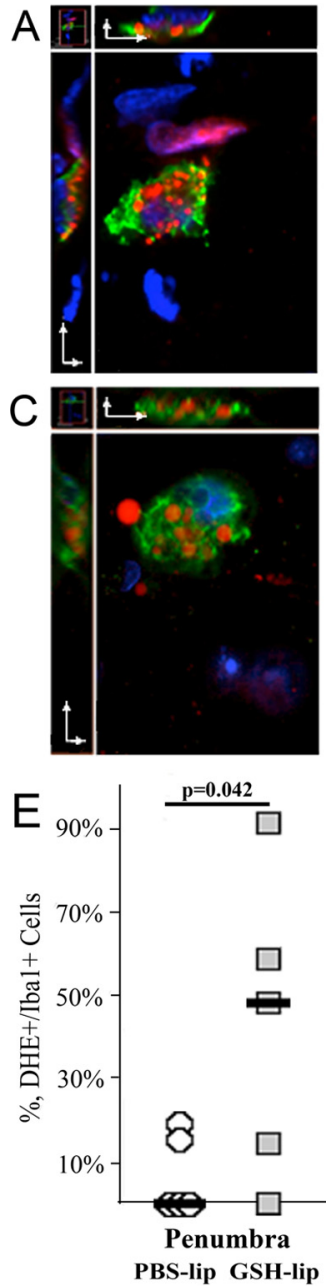
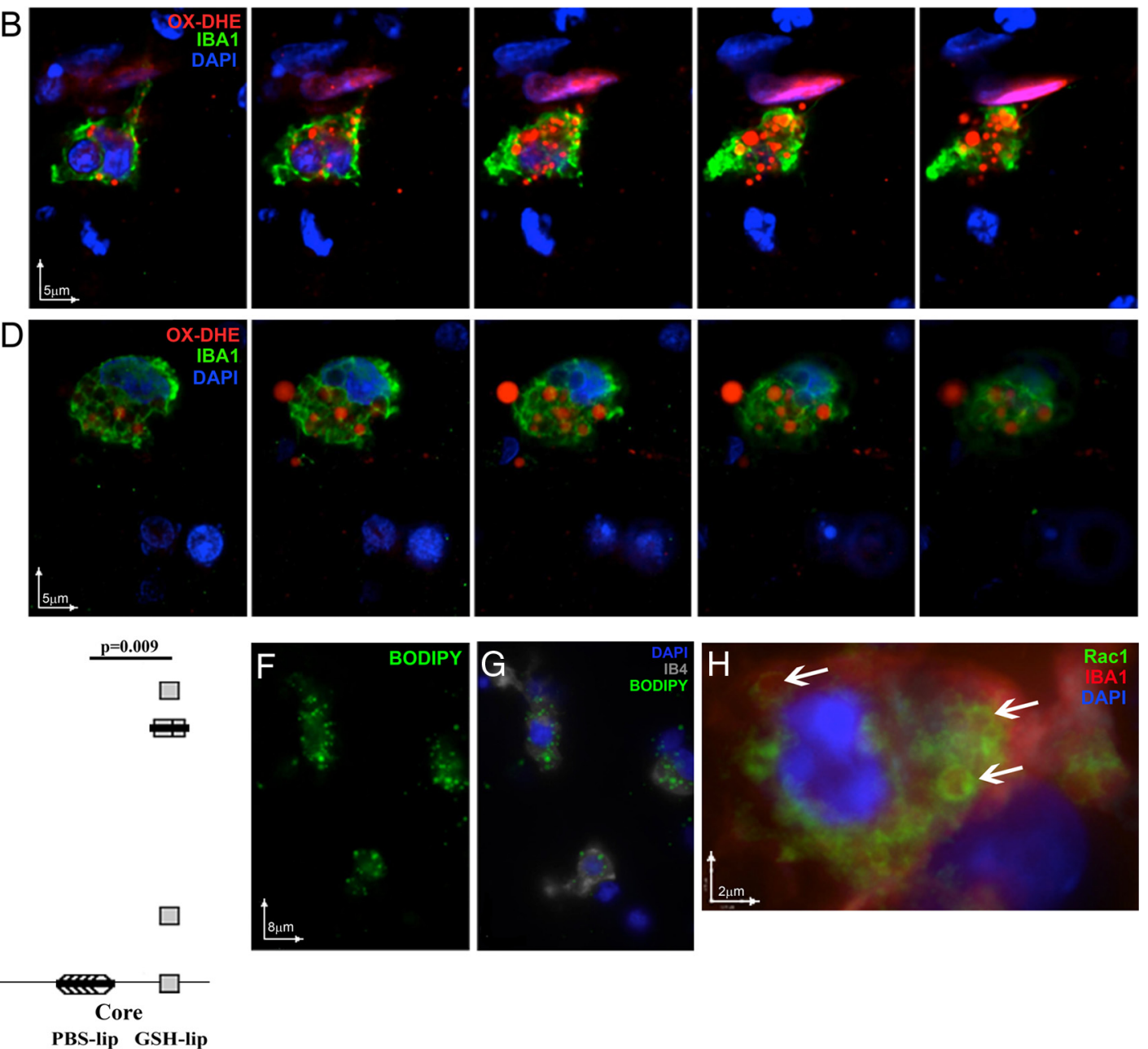

Figure 7. GSH-lip treatment potentiates $0_{2}$ - accumulation in activated microglia $24 \mathrm{~h}$ after reperfusion. $\boldsymbol{A}, \boldsymbol{B}$, An example of $\mathrm{O}_{2}$-- accumulation in an activated microglial cell, which is in contact with several neighboring cells, including an $0_{2}$-- producing endothelial cell. Shown are five from a $Z$-stack of 18 images acquired at $0.4 \mu \mathrm{m}(\boldsymbol{A}, 3 \mathbf{D}$ reconstruction image from $\boldsymbol{B})$. $\boldsymbol{C}, \boldsymbol{D}, \mathrm{An}$ example of $0_{\dot{2}}$-producing activated microglial cell which is not in contact with other cells. Shown are five from a $Z$-stack of 18 images acquired at $0.4 \mu \mathrm{m}(\boldsymbol{C}, 3 \mathbf{D}$ reconstruction image from $\boldsymbol{D})$. Green, Iba1; red, Ox-DHE; blue, DAPI. $\boldsymbol{E}$, The relative number of lba $1+$ cells with increased $0_{2}$ is significantly increased by GSH-lip treatment. $\boldsymbol{F}, \mathbf{G}$, Lipid rafts in activated microglia in PBS-lip. Green, B0DIPY $495 / 503$; gray, IB4; blue, DAPI. $\boldsymbol{H}$, Rac1 is recruited to plasma membrane in a subpopulation of activated microglia. Arrows point at ring-like patterns of Rac1 expression. Green, Rac1; red, Iba1; blue, DAPI.

mostly depleted before the first cytokine peak $(4-8 \mathrm{~h}$ after MCAO; Denker et al., 2007), and chemokine accumulation continues to increase over time. Therefore, the altered cross talk between other brain cells in the absence of microglia is the likely mechanism for continued cytokine production.

We observed an intriguingly low rate of neuronal phagocytosis in injured tissue. Removing apoptotic neurons, and hence curbing the inflammatory response due to secondary necrosis, is an important protective mechanism (Lucas et al., 2006). Limited engulfment of dying neurons might be due to insufficient socalled "find me" and "eat me" signals necessary for the engulfment of apoptotic cells by the phagocytes (Lauber et al., 2004; Mallat et al., 2005). However, we show that active caspase-3, which plays a central role in secreting factors needed to attract macrophages to apoptotic neurons (Lauber et al., 2003), is abundant. We also show that expression of several scavenger receptors involved in various steps of recognition, engulfment and processing of apoptotic cells, including CD36 (class B), CD68 (class D), and CD163 (SR type) (Denker et al., 2007), are increased in injured tissue. Insufficient migration of microglia to dying cells is unlikely to be the limiting factor in engulfment, at least through ATP/ADP-dependent migration (Haynes et al., 2006; Elliott et al., 2009), based on the expression of the $\mathrm{P}_{2} \mathrm{Y}_{12}$ receptor after reperfusion (data not shown). Elevated cytokine levels may account for the low rates of phagocytosis, because cytokines serve as repulsion signals (Mallat et al., 2005), prevent engulfment (Lauber et al., 2004), and abort physical contact between apoptotic cells and phagocytes (Lucas et al., 2006). In reperfused regions, microglia were morphologically consistent with the phagocytic phenotype-round, raffling, without leading edges-but were predominantly nonphagocytic. Importantly, even a limited rate of phagocytosis was protective, as was evident from increased calpain-mediated spectrin degradation and greater injury after microglial depletion.

Neonatal brain is prone to oxidant injury largely because of its limited capacity to metabolize $\mathrm{O}_{2}$--induced $\mathrm{H}_{2} \mathrm{O}_{2}$ accumulation (Fullerton et al., 1998; Sheldon et al., 2004). Pharmacologic inhibition of GSH production (Jain et al., 1991) or decreased GSH peroxidase activity (Sheldon et al., 2004) enhances injury after $\mathrm{H}-\mathrm{I}$, and disrupted recycling of GSH from GSSG injures primary neurons after oxygen-glucose deprivation (Vexler et al., 2003). Considering that injury in neonates is GSH dependent, we explored whether protection could be achieved by reducing ROS in

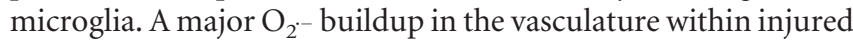



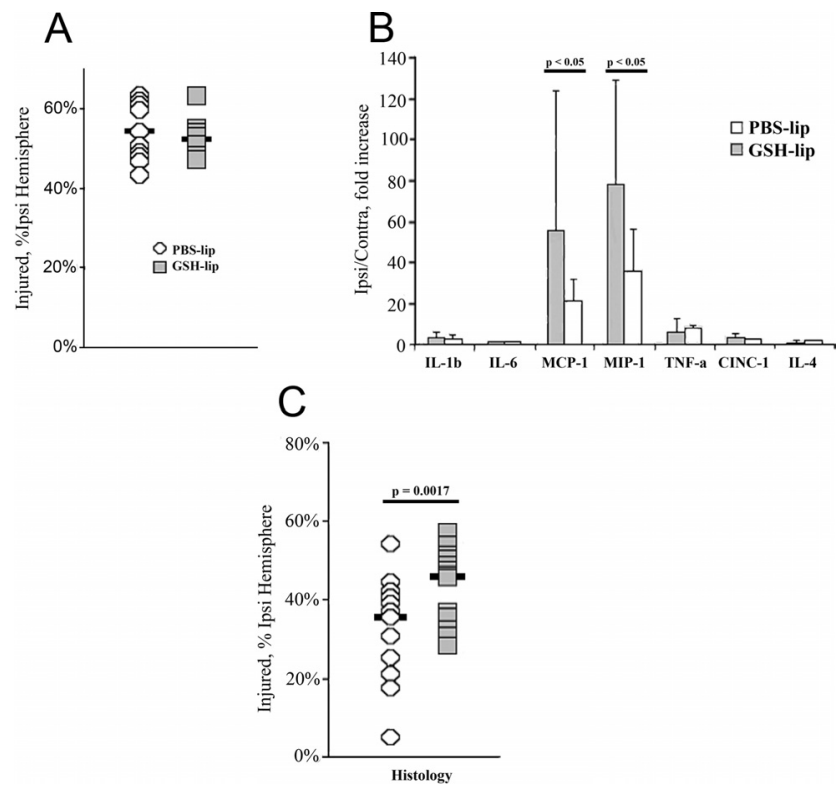

Figure 8. Increased intracellular GSH concentration in activated microglia enhances local inflammation and exacerbates subchronic injury after neonatal stroke. $A$, At $24 \mathrm{~h}$ after reperfusion, volume of injury is unaffected by increased GSH-lip. $\boldsymbol{B}, \boldsymbol{C}$, At $72 \mathrm{~h}$ after reperfusion (B) although several inflammatory chemokines are increased in injured tissue, GSH-lip treatment significantly increased the levels of microglia/macrophage chemoattractants (C). Injury volume is significantly increased by GSH-lip treatment.

regions was unaffected by a lack of microglia or increased microglial GSH, strongly suggesting that the mechanisms of $\mathrm{O}_{2-}^{- \text {gen- }}$ eration in the vasculature are independent of microglia. In activated microglia, $\mathrm{O}_{2}$ - induction was diffuse and not nearly as strong as it was in endothelial cells in PBS-lip-treated or untreated pups. Increased GSH in microglia, but not in other cell types where GSH-lip accumulation is minimal, led to a particular vesicular pattern of $\mathrm{O}_{2-}$ - increase in activated microglia-in lipid rafts and not in endosomes, lysosomes, peroxisomes, or autophages. Lipid rafts serve as hubs for receptor clustering, including the scavenger receptor CD36, the integrins CD11b and CD18, and their dynamic association with signaling molecules, including Src kinases, and their downstream protein kinase- and phosphatase-dependent pathways (Schmitz and Grandl, 2007). $\mathrm{O}_{2-}^{-}$accumulation in lipid rafts is known to generate the assembly of lipid raft domains (Zhang et al., 2010), leading to disruption of endothelial cell function (Zhang et al., 2006). Our data are consistent with the finding that lipid droplets are indicative of the inflammatory response initiated in microglia (Lalancette-Hébert et al., 2010). We show that $\mathrm{O}_{2-}^{-}$accumulation in the GSH-lip group is associated with markedly increased CD36 expression, Racl recruitment to the rafts, and assembly of lipid raft domains, events that likely account for the significantly enhanced chemokine production and increased volume of ameboid microglia.

Although increased $\mathrm{O}_{2--}$ production in response to higher GSH levels in microglia seems counterintuitive, the intracellular pattern of its accumulation (in lipid rafts) suggests several possibilities. Several enzymes in lipid rafts are thiol dependent, and an altered balance between GSH or thioredoxin and their oxidized forms affects intracellular signaling by modifying cysteines in catalytic sites of enzymes. Activation of acid sphingomyelinase is thiol dependent; it is an enzyme that converts sphingolipids to ceramide (Qiu et al., 2003), triggers lipid raft platform assembly, and activates NADPH oxidase (Nox). Nox is a major source of $\mathrm{O}_{2} \cdot$ in lipid rafts, and the nonphagocytic Nox1 isoform is neuro- toxic through $\mathrm{O}_{2--}$ production (Chéret et al., 2008). While genetic deletion of the phagocytic isoform Nox2 does not affect neonatal H-I injury (Doverhag et al., 2008), in our model the recruitment of a small GTPase Rac-1 to the membrane (required for Nox activation), along with $\mathrm{O}_{2-}$ accumulation but unchanged phagocytosis, indirectly point to Nox1 activation, which is consistent with our data on iNOS- and IL- $1 \beta$-mediated injury (Dingman et al., 2006). Altered redox signaling and cytoskeletal rearrangements induced by Rac- 1 could also signal macrophage fusion and reprogramming (Cuschieri and Maier, 2007; Helming and Gordon, 2009). Marked upregulation of CD36 by GSH-lip is another

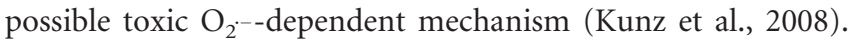

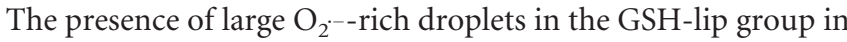
the outer leaflet of the plasma membrane also raises the possibility of extracellular $\mathrm{O}_{2-}$ - signaling through transmembrane lipid transport, possibly by endocytosis and exocytosis (Zhang et al., 2010). Based on our 3-D reconstruction immunofluorescence data, the number of microglia with increased lipid raft $\mathrm{O}_{2-}^{- \text {in }}$ physical contact with neighboring cells was unaltered by $\mathrm{GSH}$ -

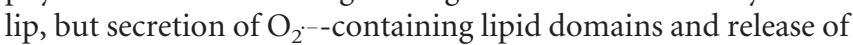
$\mathrm{O}_{2--}, \mathrm{HO}^{\circ}$, and hydrolysis products into the extracellular matrix may also cause damage. While the exact mechanisms of injury by GSH-lip_-intracellular or extracellular-are not yet understood, a pharmacologically induced shift in GSH-GSSG balance in microglia toward a reduced form exacerbates injury, likely through

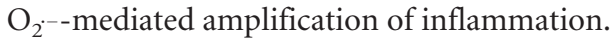

Through the depletion or selective manipulation of intracellular GSH in microglia, we show that microglia contribute to endogenous protection against early injury after neonatal stroke and that redox balance modulates the cytotoxic effects of these cells. While our data support the overall idea that $\mathrm{O}_{2-}$ - is injurious to the neonatal brain, we show a novel injury mechanism. Although there are many unanswered questions related to the underlying mechanisms of increased $\mathrm{O}_{2--}$ production in lipid rafts and the initiation of intracellular and extracellular signaling, an altered redox balance in microglia has a wide range of consequences, e.g., modulating neuroinflammation and injury in the neonatal brain. The differing patterns of $\mathrm{O}_{2^{-}}$generation after stroke in immature and adult brain delineate distinct injury mechanisms. The inability of microglia to effectively eliminate apoptotic neurons may have major functional implications for the developing brain. Further studies are needed to identify ways to enhance microglia-mediated protection.

\section{References}

Aderem A (2002) How to eat something bigger than your head. Cell 110:5-8.

Butovsky O, Ziv Y, Schwartz A, Landa G, Talpalar AE, Pluchino S, Martino G, Schwartz M (2006) Microglia activated by IL-4 or IFN-gamma differentially induce neurogenesis and oligodendrogenesis from adult stem/progenitor cells. Mol Cell Neurosci 31:149-160.

Chéret C, Gervais A, Lelli A, Colin C, Amar L, Ravassard P, Mallet J, Cumano A, Krause KH, Mallat M (2008) Neurotoxic activation of microglia is promoted by a noxl-dependent NADPH oxidase. J Neurosci 28:12039-12051.

Cho S, Park EM, Febbraio M, Anrather J, Park L, Racchumi G, Silverstein RL, Iadecola C (2005) The class B scavenger receptor CD36 mediates free radical production and tissue injury in cerebral ischemia. J Neurosci 25:2504-2512.

Cuschieri J, Maier RV (2007) Oxidative stress, lipid rafts, and macrophage reprogramming. Antioxid Redox Signal 9:1485-1497.

Denker SP, Ji S, Lee SY, Dingman A, Derugin N, Wendland MF, Vexler ZS (2007) Macrophages are comprised of resident brain microglia not infiltrating peripheral monocytes acutely after neonatal stroke. J Neurochem 100:893-904. 
Derugin N, Ferriero DM, Vexler ZS (1998) Neonatal reversible focal cerebral ischemia: a new model. Neurosci Res 32:349-353.

Derugin N, Dingman A, Wendland MF, Fox C, Bollen A, Vexler ZS (2005) Magnetic resonance imaging as a surrogate measure for histological subchronic endpoint in a neonatal rat stroke model. Brain Res 1066:49-56.

Dingman A, Lee SY, Derugin N, Wendland MF, Vexler ZS (2006) Aminoguanidine inhibits caspase- 3 and calpain activation without affecting microglial activation following neonatal transient ischemia. J Neurochem 96:1467-1479.

Doverhag C, Keller M, Karlsson A, Hedtjarn M, Nilsson U, Kapeller E, Sarkozy G, Klimaschewski L, Humpel C, Hagberg H, Simbruner G, Gressens P, Savman K (2008) Pharmacological and genetic inhibition of NADPH oxidase does not reduce brain damage in different models of perinatal brain injury in newborn mice. Neurobiol Dis 31:133-144.

Elliott MR, Chekeni FB, Trampont PC, Lazarowski ER, Kadl A, Walk SF, Park D, Woodson RI, Ostankovich M, Sharma P, Lysiak JJ, Harden TK, Leitinger N, Ravichandran KS (2009) Nucleotides released by apoptotic cells act as a find-me signal to promote phagocytic clearance. Nature 461:282-286.

Fullerton HJ, Ditelberg JS, Chen SF, Sarco DP, Chan PH, Epstein CJ, Ferriero DM (1998) Copper/zinc superoxide dismutase transgenic brain accumulates hydrogen peroxide after perinatal hypoxia ischemia. Ann Neurol 44:357-364.

Han BH, DeMattos RB, Dugan LL, Kim-Han JS, Brendza RP, Fryer JD, Kierson M, Cirrito J, Quick K, Harmony JA, Aronow BJ, Holtzman DM (2001) Clusterin contributes to caspase-3-independent brain injury following neonatal hypoxia-ischemia. Nat Med 7:338-343.

Haynes SE, Hollopeter G, Yang G, Kurpius D, Dailey ME, Gan WB, Julius D (2006) The P2Y12 receptor regulates microglial activation by extracellular nucleotides. Nat Neurosci 9:1512-1519.

Hedtjärn M, Mallard C, Hagberg H (2004) Inflammatory gene profiling in the developing mouse brain after hypoxia-ischemia. J Cereb Blood Flow Metab 24:1333-1351.

Helming L, Gordon S (2009) Molecular mediators of macrophage fusion. Trends Cell Biol 19:514-522.

Ikonomidou C, Mosinger JL, Salles KS, Labruyere J, Olney JW (1989) Sensitivity of the developing rat brain to hypobaric/ischemic damage parallels sensitivity to $\mathrm{N}$-methyl-aspartate neurotoxicity. J Neurosci 9:2809-2818.

Imai F, Suzuki H, Oda J, Ninomiya T, Ono K, Sano H, Sawada M (2007) Neuroprotective effect of exogenous microglia in global brain ischemia. J Cereb Blood Flow Metab 27:488-500.

Jain A, Mårtensson J, Stole E, Auld PA, Meister A (1991) Glutathione deficiency leads to mitochondrial damage in brain. Proc Natl Acad Sci U S A 88:1913-1917.

Kreutzberg GW (1996) Microglia: a sensor for pathological events in the CNS. Trends Neurosci 19:312-318.

Kunz A, Abe T, Hochrainer K, Shimamura M, Anrather J, Racchumi G, Zhou P, Iadecola C (2008) Nuclear factor-kappaB activation and postischemic inflammation are suppressed in CD36-null mice after middle cerebral artery occlusion. J Neurosci 28:1649-1658.

Lafemina MJ, Sheldon RA, Ferriero DM (2006) Acute hypoxia-ischemia results in hydrogen peroxide accumulation in neonatal but not adult mouse brain. Pediatr Res 59:680-683.

Lalancette-Hébert M, Gowing G, Simard A, Weng YC, Kriz J (2007) Selective ablation of proliferating microglial cells exacerbates ischemic injury in the brain. J Neurosci 27:2596-2605.

Lalancette-Hébert M, Moquin A, Choi AO, Kriz J, Maysinger D (2010) Lipopolysaccharide-QD micelles induce marked induction of TLR2 and lipid droplet accumulation in olfactory bulb microglia. Mol Pharm 7:1183-1194.
Lambertsen KL, Clausen BH, Babcock AA, Gregersen R, Fenger C, Nielsen HH, Haugaard LS, Wirenfeldt M, Nielsen M, Dagnaes-Hansen F, Bluethmann H, Faergeman NJ, Meldgaard M, Deierborg T, Finsen B (2009) Microglia protect neurons against ischemia by synthesis of tumor necrosis factor. J Neurosci 29:1319-1330.

Lauber K, Bohn E, Kröber SM, Xiao YJ, Blumenthal SG, Lindemann RK, Marini P, Wiedig C, Zobywalski A, Baksh S, Xu Y, Autenrieth IB, SchulzeOsthoff K, Belka C, Stuhler G, Wesselborg S (2003) Apoptotic cells induce migration of phagocytes via caspase-3-mediated release of a lipid attraction signal. Cell 113:717-730.

Lauber K, Blumenthal SG, Waibel M, Wesselborg S (2004) Clearance of apoptotic cells: getting rid of the corpses. Mol Cell 14:277-287.

Lucas M, Stuart LM, Zhang A, Hodivala-Dilke K, Febbraio M, Silverstein R, Savill J, Lacy-Hulbert A (2006) Requirements for apoptotic cell contact in regulation of macrophage responses. J Immunol 177:4047-4054.

Mallat M, Marín-Teva JL, Chéret C (2005) Phagocytosis in the developing CNS: more than clearing the corpses. Curr Opin Neurobiol 15:101-107.

Manabat C, Han BH, Wendland M, Derugin N, Fox CK, Choi J, Holtzman DM, Ferriero DM, Vexler ZS (2003) Reperfusion differentially induces caspase- 3 activation in ischemic core and penumbra after stroke in immature brain. Stroke 34:207-213.

Marín-Teva JL, Dusart I, Colin C, Gervais A, van Rooijen N, Mallat M (2004) Microglia promote the death of developing Purkinje cells. Neuron 41:535-547.

Monje ML, Toda H, Palmer TD (2003) Inflammatory blockade restores adult hippocampal neurogenesis. Science 302:1760-1765.

Petersen MA, Dailey ME (2004) Diverse microglial motility behaviors during clearance of dead cells in hippocampal slices. Glia 46:195-206.

Qiu H, Edmunds T, Baker-Malcolm J, Karey KP, Estes S, Schwarz C, Hughes H, Van Patten SM (2003) Activation of human acid sphingomyelinase through modification or deletion of C-terminal cysteine. J Biol Chem 278:32744-32752.

Santambrogio L, Belyanskaya SL, Fischer FR, Cipriani B, Brosnan CF, Ricciardi-Castagnoli P, Stern LJ, Strominger JL, Riese R (2001) Developmental plasticity of CNS microglia. Proc Natl Acad Sci U S A 98:6295-6300.

Schmitz G, Grandl M (2007) Role of redox regulation and lipid rafts in macrophages during Ox-LDL-mediated foam cell formation. Antioxid Redox Signal 9:1499-1518.

Sheldon RA, Jiang X, Francisco C, Christen S, Vexler ZS, Täuber MG, Ferriero DM (2004) Manipulation of antioxidant pathways in neonatal murine brain. Pediatr Res 56:656-662.

Szoka F Jr, Papahadjopoulos D (1978) Procedure for preparation of liposomes with large internal aqueous space and high capture by reversephase evaporation. Proc Natl Acad Sci U S A 75:4194-4198.

Vexler ZS, Wong A, Francisco C, Manabat C, Christen S, Täuber M, Ferriero DM, Gregory G (2003) Fructose-1,6-bisphosphate preserves intracellular glutathione and protects cortical neurons against oxidative stress. Brain Res 960:90-98.

Zhang AY, Yi F, Zhang G, Gulbins E, Li PL (2006) Lipid raft clustering and redox signaling platform formation in coronary arterial endothelial cells. Hypertension 47:74-80.

Zhang Y, Li X, Grassmé H, Döring G, Gulbins E (2010) Alterations in ceramide concentration and $\mathrm{pH}$ determine the release of reactive oxygen species by Cftr-deficient macrophages on infection. J Immunol 184:5104-5111.

Zito MA, Koennecke LA, McAuliffe MJ, McNally B, van Rooijen N, Heyes MP (2001) Depletion of systemic macrophages by liposome-encapsulated clodronate attenuates striatal macrophage invasion and neurodegeneration following local endotoxin infusion in gerbils. Brain Res 892:13-26. 